5 Jenkins R, Gulbinat W, Manderscheid R, Baingana F, Whiteford H, Khandelwal $\mathrm{S}$, et al. The mental health country profile: background, design and use of a systematic method of appraisal. The International Consortium on Mental Health Policy and Services: objectives, design and project implementation. Int Rev Psychiatry 2004;16:31-47.

6 Tomov T, Mladenova M, Lazarova I, Sotirov V, Okoliyski M. Bulgaria mental health country profile. Int Rev Psychiatry 2004;16:93-106.

7 Puras D, Germanavicius A, Povilaitis R, Veniute M, Jasilionis D. Lithuania mental health country profile. Int Rev Psychiatry 2004;16:117-25.

8 Sharashidze M, Naneishvili G, Silagadze T, Begiashvili A, Sulaberidze B,
Beria Z. Georgia mental health country profile. Int Rev Psychiatry 2004:16:107-16.

9 Global Network for Research in Mental and Neurological Health. www.mental-neurological-health.net/ (accessed 18 Jul 2005).

10 Jenkins R. Supporting governments to adopt mental health policies. World Psychiatry 2003;2:14-9.

11 Law of the Russian Federation 3185-1 02 Jul 1992. "On psychiatric care and guaranties of rights of citizens during its provision." The Duma of the Russian Federation, 1992.

12 Open Society Mental Health Initiative. www.soros.org/initiatives/mhi (accessed 18 Jul 2005).

\title{
Combating non-communicable diseases
}

\section{Public health experts have failed to make the case for adequate funding}

$\mathrm{N}$ on-communicable diseases account for most of the global burden of disease. This share is forecast to grow in the decades ahead, particularly in low income and middle income countries. ${ }^{1}$ In the countries of eastern Europe, chronic noncommunicable diseases among people of working age drive high rates of adult mortality. ${ }^{2}{ }^{3}$ This obviously concerns the lives of the affected individuals and their families, but who else should be concerned about this?

Non-communicable diseases have not been considered sufficiently important to be included among the health related targets of the Millennium Development Goals, leading some to question the relevance of these goals for Europe's transitional countries. ${ }^{4}$ The resources earmarked for them are extremely low. Despite the obvious epidemiological trends, few countries have implemented comprehensive policies for preventing and controlling non-communicable diseases. ${ }^{5}$

The public health community has not made a sufficiently strong case for the importance of noncommunicable diseases. Decision makers are unaware of the full health and economic burdens attributable to these diseases. This lack of awareness may have held back the actions needed to curb this rising toll.

A cynical, but not uncommon, response argues that, because deaths from non-communicable diseases occur mainly towards the end of an individual's working life, any relevant expenditure on public health would simply lengthen the lives of those who have already delivered their lifetime contribution to society. This argument is flawed.

A substantial share of mortality from noncommunicable diseases afflicts people of prime working age. A period of poor health typically precedes mortality and, although the association between mortality and morbidity is not uniform, eastern Europe has high morbidity as well as mortality from these diseases. ${ }^{7}$ Such morbidity reduces the productivity and active participation of people in work. ${ }^{8}$ Furthermore, adults respond to chronic illness in ways that may obscure direct effects on the labour market. Such coping responses may involve taking a spouse out of work or a child out of school to care for an ill member of the household. These impacts on others should also be considered as costs. ${ }^{9}$ Lastly, those who are not part of the formal labour force, such as pensioners, also contribute to economic outcomesparticularly when in good health-even though the benefits rarely appear in official measures. ${ }^{10}$
Taken together, these microeconomic effects may well add up to a substantial macroeconomic impact on a country's overall development; and adult mortality is known to be a reliable predictor of subsequent economic growth. ${ }^{11}$

All of these arguments sound highly plausible. However, plausibility is rarely viewed by policy makers as a substitute for rigorous empirical research. We are only beginning to build the case, ${ }^{12}$ and we need empirical evidence. Nevertheless, progress towards restoring balance in the agenda for global health will almost certainly be furthered by economic evaluations of the impacts of non-communicable diseases. If we really intend to make a difference to health in eastern Europe and beyond we must use the universal language of decision makers, based on sound epidemiological, clinical, and economic evidence.

\section{Patricio V Marquez lead health specialist}

Europe and Central Asia Region, World Bank, 1818 H Street NW, Washington 20433 (pmarquez@worldbank.org)

\section{Marc Suhrcke economist}

World Health Organization, European Office for Investment for Health and Development, Palazzo Franchetti, S Marco 2847, I-30124 Venice, Italy

1 World Health Organization. The world health report 2003: shaping the future. Geneva: WHO, 2003.

2 McMichael AJ, McKee M, Shkolnikov V, Valkonen T. Mortality trends and setbacks: global convergence or divergence? Lancet 2004:363:1155-9.

World Bank. Dying too young: addressing premature mortality and ill health due to non communicable diseases and injuries in the Russian Federation. Washington, DC: World Bank (in press).

4 World Bank. Millennium development goals for health in Europe and Central World Bank. Millennium development goals for health in Europe and Central Asia. Relevance and policy implications. Washington, DC: World Bank, 2004.
Beaglehole R, Yach D. Globalisation and the prevention and control of Beaglehole R, Yach D. Globalisation and the prevention and control of
non-communicable disease: the neglected chronic diseases of adults. non-communicable disease: the neglected chronic diseases of adults.
Lancet 2003;362:903-8.

6 Commission on Macroeconomics and Health. Macroeconomics and health: investing in health for economic development. Geneva: World Health Organization, 2001.

7 Andreev EM, McKee M, Shkolnikov VM. Health expectancy in the Russian Federation: a new perspective on the health divide in Europe. Bull WHO 2003;81:778-87.

8 Currie J, Madrian BC. Health, health insurance and the labor market. In: Ashenfelter O, Card D, eds. Handbook of labor economics. Vol 3. New York: Elsevier Science, 1999:3309-415.

9 Feachem RG, Kjellstrom T, Murray CMJ, Over M, Phillips MA, eds. The health of adults in the developing world. New York: Oxford University Press for the World Bank, 1992.

10 Chadeau A. Measuring household activities. Rev Income Wealth 1985;31:237-53.

11 Suhrcke M, Rocco L, McKee M, Urban D, Mazzucco S, Steinherr A. Economic consequences of non-communicable diseases and injuries in the Russian Federation. Venice: WHO European Office for Investment for Health and Development: Venice, 2005.

12 Leeder S, Raymond S, Greenberg H, Liu H, Esson K. A race against time: the challenge of cardiovascular disease in developing countries. New York: Center for Global Health and Economic Development, Earth Institute, Mailman School of Public Health, Columbia University, 2004. 